\title{
Enhancing Crowdsourcing Success: the Role of Creative and Deliberate Problem-Solving Styles
}

\author{
Dominik Mahr • Aric Rindfleisch • Rebecca J. Slotegraaf
}

Published online: 25 February 2015

(C) Springer Science+Business Media New York 2015

\begin{abstract}
A growing number of firms are using crowdsourcing platforms to actively solicit the skills of external entities to help them solve innovationrelated problems. Despite its increasing popularity, crowdsourcing has produced mixed success, because few external experts provide helpful solutions. The current research examines this issue by exploring why some external solvers are more successful than others. Grounded in dual-processing theory, this study combines survey and archival data to assess the impact of creative versus deliberate problem-solving styles on solving success. The results indicate that both styles can be effective, but their relative success depends on the amount of time a solver invests in a solution and his or her degree of contextual familiarity with the problem. Specifically, creative (deliberate) styles are more effective under conditions of high (low) contextual familiarity and shorter (longer) time investments. When solvers employ both styles, overall problem-solving success declines.
\end{abstract}

Keywords Open innovation $\cdot$ Crowdsourcing $\cdot$ Problem solving $\cdot$ Expertise

\section{Mahr}

Maastricht University, Maastricht, The Netherlands

e-mail: d.mahr@maastrichtuniversity.nl

\author{
A. Rindfleisch $(\square)$ \\ University of Illinois, Champaign, IL, USA \\ e-mail: aric@illinois.edu \\ R. J. Slotegraaf \\ Indiana University, Bloomington IN, USA \\ e-mail: rslotegr@indiana.edu
}

\author{
Innovation happens everywhere, there is simply more \\ elsewhere than here. \\ —Goldman and Gabriel [31, p. 27].
}

\section{Introduction}

Innovation is a top strategic priority and a key driver of corporate growth and profitability $[35,42]$. In the past decade, several firms have begun to realize that their innovation goals cannot be fully satisfied through internal resources and capabilities [17, 41, 74]. Thus, firms such as IBM, General Motors, and Procter \& Gamble (P\&G) have moved beyond internal innovation efforts to embrace various external organizations, such as suppliers [21], competitors [63], and institutions [49]. Firms including Eli Lilly, P\&G, SAP, BMW, and General Electric also have begun to open their innovation process to external individuals through crowdsourcing platforms such as Kaggle, Innoget, and InnoCentive [10, 51, 74].

These platforms enable firms to broadcast their innovationrelated problems anonymously across a network of thousands of external experts, who select problems to work on and compete for the best solution in exchange for a (modest) monetary reward $[1,2]$. Hence, this approach holds the promise of providing firms with relatively low-cost solutions to vexing problems, under the protection of anonymity [15]. ${ }^{1}$ For example, an oil company seeking an innovative means to recover spilled tanker oil used InnoCentive to obtain a fast and effective solution from an individual expert who suggested that the firm employ a vibration device commonly used in the concrete industry. Unfortunately, these success stories are uncommon, because most crowdsourcing platforms (1) obtain

\footnotetext{
${ }^{1}$ Although most external problem-solving platforms provide seekers with anonymity, some do not (e.g., Innoget, eYeka).
} 
relatively few submissions from potential solvers and (2) the vast majority of these submissions do not result in effective solutions [43]. This limited success constitutes a considerable concern for firms, because a high rate of rejection may discourage solvers from submitting in the future, which may force firms to look elsewhere for answers. This issue is also relevant for innovation scholars, because the predictors of innovation success largely emerge from studies of internal innovation activity and may be less relevant in this new domain [35]. Thus, understanding why some external solvers are more successful than others is an important issue for innovation scholars and practitioners.

Research to date suggests that, at a macro level, crowdsourcing innovation platforms are capable of enhancing innovation success [43, 61]. However, little is known about the factors that separate successful solvers from the rest of the pack. To address this issue, we focus on the problem-solving styles (i.e., creative vs. deliberate) that external solvers employ to solve an innovation-related problem. These styles, which are deeply ingrained in the individual solver's approach to processing problem-relevant information and developing solutions, influence problem-solving performance $[24,53,62$, 67]. Our focus on creative and deliberate styles is grounded in dual processing literature, which indicates that problemsolving approaches are guided by either an associative (i.e., creative) or a rule-based (i.e., deliberate) information processing approach $[23,46,64,65] .^{2}$

In addition to focusing on the problem-solving styles of individual solvers, our research recognizes that the effectiveness of these styles is situationally contingent $[25,46,52,57]$. Thus, we examine the degree to which the success of these styles depends on two distinctive characteristics of an external problem-solving setting: temporal investment and contextual familiarity. Temporal investment refers to the amount of time that a solver dedicates to developing a proposed solution to a seeker's problem. Unlike members of a firm's internal product development team, external solvers have substantial discretion over the amount of time they invest in solving an innovation problem. Contextual familiarity refers to the degree to which a solver has knowledge of the firm seeking the solution. In contrast to the substantial familiarity that a firm's internal product development team has with the firm (e.g., its goals, resources, strategies), external solvers typically are unaware of even the identity of the firm seeking the solution, because most firms that employ innovation crowdsourcing platforms wish to remain anonymous. This theoretical focus on solver styles and situational characteristics provides a novel

\footnotetext{
${ }^{2}$ Other authors use different terminology for similar conceptualizations. For example, McDonough and Barczak's [53] problem-solving orientations are rooted in individual work performance literature and therefore use the terms innovative (equivalent to our creative styles) and associative (deliberate styles).
}

perspective on innovation crowdsourcing in particular and open innovation in general.

On the basis of these theoretical underpinnings, we develop three hypotheses regarding the interactive effects of the two problem-solving styles. To examine these hypotheses, we draw on both survey and archival data to assess the influence of creative and deliberate styles, contextual familiarity, and temporal investment on the success of 453 external solvers. We conclude with a general discussion that summarizes our findings and highlights the implications of our investigation.

\section{Conceptual Framework}

\subsection{Innovation Crowdsourcing}

Although firms traditionally have conducted innovation activities in-house, the recent rise of online innovation crowdsourcing platforms such as InnoCentive have enabled firms to locate external expertise more easily while still protecting their intellectual property $[10,17,22,51]$. Firms usually employ these platforms to seek external help for innovation-related problems that they have been unable to solve internally [74]. A brief description of these problems is usually posted (for a specified time period) as an anonymous call for proposals to a platform's set of registered solvers. The solvers are typically well-educated, with highly specialized expertise across a variety of domains. Only a small subset of solvers submits proposed solutions to any given problem. To protect the identity of the solution-seeking firm, these solutions are collected by the platform intermediary, which passes them along to the seeker firm after the specified deadline has passed. The seeker then reviews all submissions and decides which, if any, represents a successful solution to its problem. The solver with the winning submission typically receives a monetary reward, while the seeker obtains intellectual property rights to the solution $[43,68] .^{3}$

As this description reveals, the external problem-solving process differs notably from the solving procedures typically employed in internal innovation. For example, for internal innovation activity, the firm typically assigns individual employees to work on a given project for a specified period of time. In contrast, external solvers self-select a problem and have complete discretion over the amount of time (prior to the submission deadline) they will devote to solving it [2]. Thus, temporal investment is a distinguishing feature of innovation crowdsourcing and is likely to display considerable variance across various projects.

\footnotetext{
${ }^{3}$ Solvers whose submissions are not selected retain the full intellectual property rights to their solutions. Unsuccessful solvers rarely receive feedback on the proposed solution and do not have the opportunity to rework failed submissions.
} 
A second key distinction is the solver's degree of contextual familiarity with the problem itself. In contrast to an internal setting, in which project team members have a high degree of familiarity with their firm, external solvers usually do not know the identity of seeker firms; the posted problem descriptions are crafted carefully to focus on technical requirements without revealing the identity of the seeker, its prior solution attempts, or its broader strategic intent. As a result, the nature of problem solving in an external setting differs notably from internal innovation processes in terms of the solver's degree of contextual familiarity.

\subsection{Problem-Solving Styles}

To understand why some external solvers are more successful than others, we examine the role of enduring solver styles. We focus on two specific styles (i.e., creative and deliberate) that people may use to solve innovation-related problems $[8,45$, $47,53]$. Although conceptually and empirically distinct, these two styles share a common theoretical connection to dual processing theories in social psychology (e.g., [23, 46, 64]). Dual processing theories have been applied across a broad range of contexts. Thus, this body of literature exhibits some conceptual variation in the labels given to these two processes and the nature of their relationship [40]. Nonetheless, there is considerable agreement regarding dual processing's defining characteristics [65].

Essentially, all dual processing theories suggest that human information processing in general, and problem-solving approaches in specific, are guided by two distinct but related cognitive systems. One system is holistic, intuitive, and effortless whereas the other is analytic, logical, and effortful. Creative styles are guided largely by the former system, while deliberate styles are guided by the latter. Although both processes have been positively associated with problem-solving success $[6,56,64]$, neither is inherently superior, because their effectiveness is contingent on the situation [25, 46, 52, 57]. Thus, rather than focusing on the direct effect of these two styles, we account for the two distinguishing characteristics of the external problem-solving setting and explore their interactive effects with temporal investment and contextual familiarity, as well as their combined effect on problem-solving success.

\subsection{Creative vs. Deliberate Problem-Solving Styles}

Creative problem-solving styles are practices people use to solve problems by developing imaginative solutions through an intuitive approach $[6,66,76]$. Solvers who use creative styles focus holistically on the problem and its broader contextual setting [39]. Familiarity with a contextual setting allows a solver to develop a solution by drawing associations with related domains [7, 46, 53]. This type of holistic approach facilitates heuristic, simultaneous processing rather than rule-based, sequential processing $[57,65]$. Thus, creative problem-solving styles offer a means to develop solutions quickly and often reveal flashes of insight that occur in a serendipitous manner [66]. For example, many firms attempt to stimulate creative problem solving with brainstorming techniques to generate dozens or hundreds of ideas within hours [76].

In contrast, deliberate problem-solving styles are practices that people use to solve problems by developing logical solutions through an analytical approach [24, 45, 57, 62]. Solvers who use deliberate styles focus more on the specifics of a particular problem, rather than its contextual setting [39], and apply a set of well-defined rules and procedures [53]. Goldenberg and Mazursky [30] outline a series of analytical templates that can apply to different problems across various contexts. Because deliberate problem-solving approaches tend to be highly structured and require the application of sequential sets of rules, they seldom produce flashes of insight and may require considerable investments of time [46, 65]. For example, the TRIZ innovation technique requires solvers to proceed through more than 100 sequential steps [5].

\section{Hypotheses}

Overall, given the distinct associations of creative and deliberate problem-solving styles with time and context, we propose that these two styles interact differently with temporal investment and contextual familiarity to influence solving success.

\subsection{Interaction with Temporal Investment}

By definition, external solvers are independent agents, with considerable discretion over the amount of time they devote to solving a seeker's problem $[68,70]$. In addition to the time devoted to developing a potential solution, solvers decide how much time to invest in understanding the problem and conveying their solution. ${ }^{5}$ Greater time investments should be more valuable for solvers who rely on deliberate problemsolving styles, considering the logical, step-by-step approach that characterizes the deliberate style [24, 65]. The steps typically follow a sequential manner and require substantial effort

\footnotetext{
${ }^{4}$ This deliberate problem-solving technique (Theory of Inventive Problem Solving), developed by Altshuller [5], has recently been rediscovered and employed by several global firms, including Boeing, Dow, and P\&G. ${ }^{5}$ Solvers also have considerable discretion over the amount of money they invest in a solution. However, this financial investment is typically quite small and pales in comparison to their temporal investment. Our data reveal that $54 \%$ of solvers do not invest any money and $86 \%$ invest less than $\$ 100$ per solution. In contrast, the average solver in our sample invested nearly $40 \mathrm{~h}$ per solution.
} 
in terms of dividing a problem into smaller elements, logically analyzing each element, and considering the pros and cons of various possible solutions $[8,46]$. This problem-solving approach is "effortful and time-consuming" ([65], p. 112) and often involves deferred (rather than immediate) action [23]. As a result, we expect temporal investment to enhance the success of deliberate problem-solving styles.

In contrast, creative problem-solving styles are considerably less time intensive $[23,65]$. The retrieval of cognitive associations and their heuristic application is often conducted quickly and automatically $[46,57,64]$. According to Smith and DeCoster [65, p. 123], creative styles are "quick, intuitive and relatively effortless." Unlike the step-by-step approach of deliberate problem solving, creative problem solving usually relies on intuition and flashes of insight. Thus, creative styles employ simultaneous rather than sequential processing [64]. This suggests that higher temporal investment would offer limited value for this problem-solving approach.

According to some scholars, creative processes can be enhanced by an incubation period, in which temporary withdrawal from the problem allows a solver to form new conceptual linkages and generate possible creative breakthroughs [16]. The influence of time on the success of creative problem-solving approaches has prompted a few investigations $[7,16]$. However, extant studies offer mixed results and reveal that temporal investment exerts a full range of effects (none, positive, negative) on problem-solving success. Thus, the impact of time on the success of creative styles appears murky at best. We propose that temporal investment has less of an impact on the success of creative problemsolving styles than on deliberate styles.

$\mathbf{H}_{\mathbf{1}}$ The effect of problem-solving styles on external problem-solving success is moderated by the solver's degree of temporal investment. A high degree of temporal investment enhances the success of deliberate styles more than creative styles.

\subsection{Interaction with Contextual Familiarity}

Because crowdsourcing is characterized by a relatively low degree of contextual familiarity, problem solvers must try to develop solutions for abstract problems without the benefit of knowing the identity of the firm for which they are proposing a solution. Given this lack of identity knowledge, solvers may have little idea about the problem's industry context or potential application. Contextual familiarity may be advantageous for deliberate problem-solving styles, because greater knowledge about the identity of the seeker would provide more input to the analytical and logical processes that characterize this style. However, contextual familiarity should be helpful to the solver, regardless of the problem-solving mode employed, and we believe its lack may be more problematic for solvers who employ creative problem-solving styles.

Given their holistic focus and intuitive approach, solvers who adopt creative styles depend on contextual information, such as the problem background and application, to help generate appropriate solutions $[6,66]$. This information is essential for drawing associations with related domains [7, 23, 52]. According to Hirschman [37, p. 288], such associations establish important conceptual linkages that allow people to recall cognitive scripts that "mentally represent the problem context." Epstein et al. [23, p. 401] similarly suggest that creative problem solving "operates by context-specific, heuristic rules." Thus, creative styles rely heavily on contextual information to retrieve cognitive associations and heuristically apply them to generate appropriate solutions $[6,46]$. Therefore, we expect a lack of contextual information to hamper the success of these creative problem-solving styles.

In contrast, the analytical and structured nature of deliberate problem-solving styles depends considerably less on contextual information for developing an appropriate solution $[57,65]$. Unlike the cognitive associations and heuristic applications that underlie creative styles, deliberate styles rely on highly structured, largely invariant analytical procedures $[46$, $53,64]$. These procedures are highly effective at encoding and processing abstract symbols, words, and numbers across a wide range of contextual settings [23, 57]. As Epstein et al. [23, p. 401] note, deliberate styles largely "operate by abstract, general rules guided by analysis and logic." Thus, we expect a lack of contextual information to be less detrimental to the effectiveness of deliberate problem-solving styles than of creative problem-solving styles.

$\mathbf{H}_{\mathbf{2}}$ The effect of problem-solving styles on external problem-solving success is moderated by the solver's familiarity with the problem context. A low degree of contextual familiarity hampers the success of creative styles more than of deliberate styles.

\subsection{Interaction Between Creative and Deliberate Problem-Solving Styles}

Although creative and deliberate styles represent two different problem-solving approaches, they do not lie on opposite ends of a continuum. According to a growing body of research in dual processing theories, intuitive and analytical problemsolving approaches are orthogonal rather than oppositional (e.g., $[23,40,53,64,65])$. Thus, an external problem solver can employ both creative and deliberate styles. We accordingly examine the interaction effect of these two styles on external problem-solving success.

According to dual-processing theory, the combined effect of intuitive and analytical problem-solving approaches could be synergistic or antagonistic [23, 64]. As Smith and DeCoster 
$[65$, p. 123$]$ note, "Sometimes they provide different answers... In other cases, they work more cooperatively." Theoretically, problem-solving processes may benefit from the sequential use of both styles [40]. For example, creative styles might serve to develop a new product concept, and then deliberate styles can be used to evaluate and refine this concept. However, this type of sequential approach seems unlikely in an external problem-solving context, because the challenges that solvers face typically require them to perform a single problem-solving task (i.e., ideation or testing, but rarely both). Synergies between creative and deliberate styles could arise in a collaborative team setting, in which individual members employ different problem-solving styles and then combine their efforts [29]. However, this collaboration is unlikely in an external problem-solving setting, because most solvers work in isolation [43].

Creative styles are temporally independent but contextually dependent, whereas deliberate styles are temporally dependent but contextually independent. Thus, they share little connection in terms of their relationship to our conditional moderators of problem-solving success. Instead, these two problem-solving styles appear well suited for contrary problem conditions [57]. Hence, the use of both creative and deliberate styles may hamper external problem-solving success.

$\mathbf{H}_{3}$ The interaction of creative and deliberate problemsolving styles has a negative effect on external problem-solving success.

\section{Research Design}

\subsection{Data Collection and Sample}

To obtain a sample of solvers, we collaborated with InnoCentive, the world's first (founded in 2001) and largest (170,000 solvers) innovation crowdsourcing platform. ${ }^{6}$ InnoCentive provided the names and e-mail addresses of all problem solvers who submitted solutions to challenges posted on Innocentive.com. From this list, we selected a recent 2-year time frame, during which InnoCentive posted 260 challenges, which attracted submissions from 1711 solvers.

InnoCentive e-mailed a pre-announcement to all solvers, alerting them to our study and requesting their cooperation. Approximately 1 week after this alert, each solver was sent a personalized e-mail with a link to a web-based survey. As an incentive to participate, solvers were promised a summary of our key findings. Ten days later, a reminder e-mail was sent to all solvers who had not yet responded. After accounting for

\footnotetext{
${ }^{6}$ InnoCentive began as a spin-off of Eli Lilly, but its current clients hail from a variety of industries (e.g., chemical, consumer packaged goods, energy, software); for details, see Lakhani [48].
}

non-deliverable e-mails and removing incomplete surveys (i.e., missing at least half the data), our final sample consisted of 453 usable surveys, for a response rate of $30 \%$, which compares favorably with prior surveys in this domain [43]. We assessed potential non-response bias by comparing the characteristics of respondents versus non-respondents. This comparison revealed no significant differences in their country of residence or time since registering as an InnoCentive solver. As an additional check, we compared the response patterns of early and late responses [9] but found no significant differences in the number of submissions, number of awards, level of problem-solving styles, degree of temporal investment, or degree of contextual familiarity. In aggregate, these assessments suggest that non-response bias is unlikely.

Demographically, our respondents are predominately highly educated (60\% hold an advanced degree), middle age $(M=$ 49 years) men (90\%) who have considerable work experience $(M=25$ years). This demographic profile closely matches the profile in Jeppesen and Lakhani's [43] recent survey and mirrors InnoCentive's population of active solvers.

\subsection{Measures and Validation}

Our survey instrument assessed solvers' problem-solving styles, temporal investment, contextual familiarity, and sociodemographics. When possible, we adapted measures from prior research. We pretested our instrument with two InnoCentive managers and six innovation scholars not involved in this study. From these results, we made several minor refinements. Except where noted, all scales used seven-point, Likert formats, where 7 indicated "strongly agree." The multi-item measures are detailed in the Appendix, and the key descriptive statistics and correlations are in Table 1.

\subsubsection{Problem-Solving Styles}

We measured creative problem-solving styles $(\alpha=.75)$ with a six-item scale that captured the degree to which solvers attempted to think outside of the box, brainstorm a large number of possible solutions, and leverage knowledge from other domains. This measure drew from concepts and measures developed by Amabile [6], Besemer and O'Quin [13], and Sloman [64]. We measured deliberate problem-solving styles $(\alpha=.77)$ with a six-item scale related to the degree to which solvers employed an analytical, structured, and logical problem-solving approach. This measure was developed on the basis of prior conceptualizations and adapted from various measures of deliberate problem solving [4, 24, 64].

\subsubsection{Moderators}

Because both temporal investment and contextual familiarity are relatively concrete, objective constructs, we assessed each 


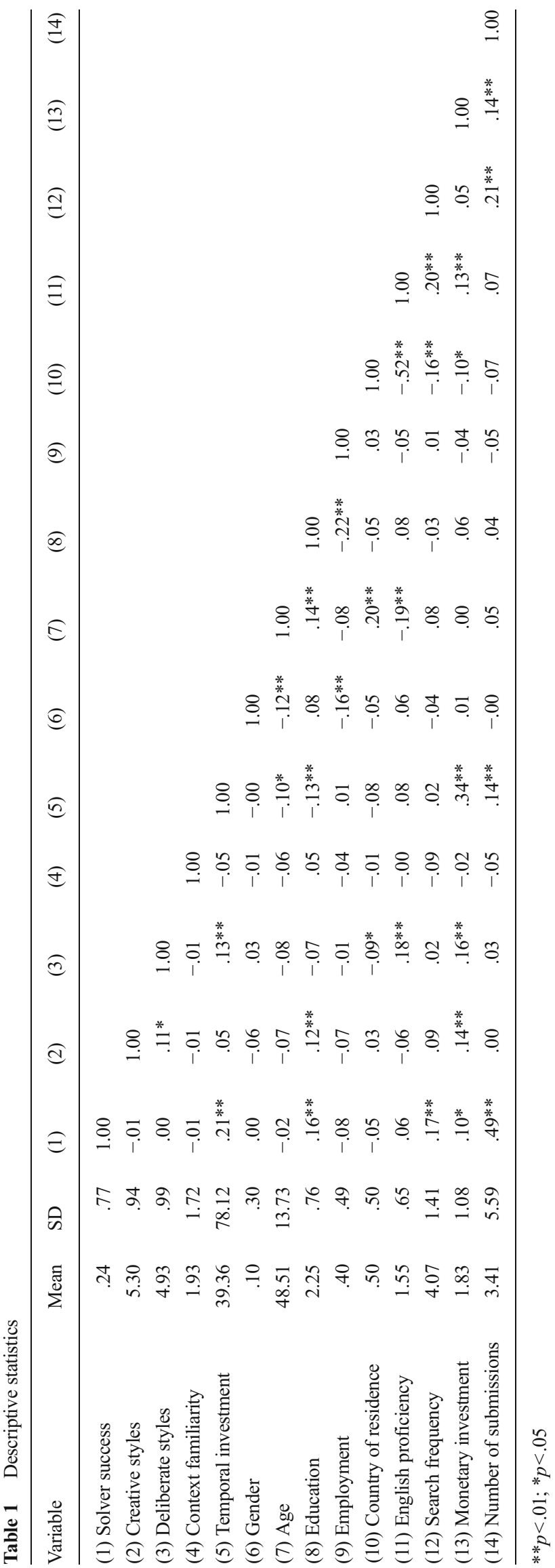

with a single item, as recommended by Bergkvist and Rossiter [12]. Specifically, we assessed temporal investment by asking, "On average, how much time (in hours) has it taken to develop solutions for each challenge?" We measured solvers' contextual familiarity by asking, "How often were you aware of the identity of the seeker?" (1 = "never," 7 = "always"). On average, solvers possessed a high degree of temporal investment $(M=39.4)$ and a low degree of contextual familiarity $(M=$ 1.93).

\subsubsection{Solving Success}

To minimize the risk of common method bias, our dependent variable was obtained from archival data [60]. Specifically, InnoCentive provided information about the number of challenges successfully solved by each respondent, which served as an indicator of solving success. This indicant has been similarly employed in prior studies in this domain [43]. Among the 453 respondents, only 68 (15\%) successfully solved an InnoCentive challenge. This percentage is somewhat higher than the overall success rate for InnoCentive's solver base, but congruent with prior research [43].

\subsubsection{Control Variables}

We assessed several control variables. To control for the possible influence of sociodemographic characteristics, we asked solvers to report their age, gender $($ male $=0$, female $=1)$, education (bachelor's $=1$, master's $=2$, doctoral $=3$ ), employment status (independently employed $=0$, employed by a firm $=1$ ), and country of residence (non-US $=0, \mathrm{US}=1$ ). Because many solvers reside in foreign countries, we also assessed their degree of English proficiency (native=1, fluent $=2$, intermediate $=3$, beginner $=4$ ). In addition, we controlled for how frequently solvers searched InnoCentive challenges (never $=1$, daily $=7$ ) and their average monetary investment in their solutions (none $=1, \$ 1-\$ 50=2$, $\$ 51-\$ 100=3$, more than $\$ 100=4$ ). Finally, because solving success likely relates to submission frequency, we obtained (from InnoCentive) the number of challenges for which our respondents submitted solutions (number of submissions).

\subsubsection{Validation}

We validated our multi-item measures (i.e., creative and deliberate problem-solving styles) using confirmatory factor analysis. We analyzed this model using LISREL 8.8 [44], which indicated a strong degree of fit $\left(\chi^{2}(51)=133.5\right.$, $p<.01$; confirmatory fit index $=.95$; non-normed fit in$\mathrm{dex}=.94$; root mean square error of approximation $=.06$; standardized root mean residual $=.06$ ). We assessed the discriminant validity of the measures by employing Fornell and Larcker's [26] test of shared variance between latent 
constructs, which revealed that the squared correlation between creative and deliberate styles did not exceed each construct's average variance extracted $(p<.01)$. Thus, the measures displayed adequate discriminant validity.

\section{Results}

Prior to examining our predictions, we controlled for potential selection bias [36], because solver success may be affected by the nature of the particular challenges that each solver selects. We adopted a two-stage analytical approach, in which we first corrected for potential selection bias (Stage 1) and then controlled for this potential bias in our regression model (Stage 2).

\subsection{Selection Bias Correction}

In Stage 1, we used a version of the Heckman [36] two-stage model, adapted for continuous variables (i.e., number of submissions by each solver) $[27,28]$. Specifically, we regressed the influence of both solver-specific (i.e., age, gender, education, employment status, country of residence, English proficiency) and project-specific (i.e., challenge duration, award amount, number of competing submissions) variables on each respondent's submissions. The integration of the selection correction improved the model $(p<.05)$, indicating the usefulness of Stage 1 for correcting for selection bias. The results indicated that only the solver's education $(\beta=-6.45 ; p<.01)$ and the project's challenge duration $(\beta=-.40 ; p<.01)$ related to submission frequency.

\subsection{Hypothesis Testing}

In Stage 2, we incorporated the residuals from Stage 1 and tested our hypotheses using zero-inflated Poisson (ZIP) regression [3, 11, 32]. The use of ZIP regression provided two key benefits compared with standard ordinary least squares regression. First, ZIP regression accounts for non-normally distributed dependent variables by weighting their parameter estimates by their probability of success. In our data set, solver success was non-normally distributed, consisting of few successes and many failures. Second, ZIP regression accounted for differences in a dependent variable's rate of occurrence by assessing the degree to which it was "exposed" to such opportunities. Thus, we controlled for the fact that a solver who submits solutions to multiple challenges has an opportunity to be more successful than one who submits to only a single challenge.

We estimated two separate ZIP regression models (Models 1 and 2) and report the results in Table 2. We estimated the direct effects of our two problem-solving styles, context familiarity, and temporal investment in Model 1, then included the hypothesized interactions in Model 2. Prior to constructing
Table 2 ZIP estimation results

\begin{tabular}{|c|c|c|}
\hline & \multicolumn{2}{|c|}{ Effect on solver success } \\
\hline & Model 1 & Model 2 \\
\hline \multicolumn{3}{|l|}{ Problem-solving styles } \\
\hline Creative styles (CS) & $-.25^{*}$ & -.11 \\
\hline Deliberate styles (DS) & -.07 & -.10 \\
\hline \multicolumn{3}{|l|}{ Moderators } \\
\hline Temporal investment (TIME) & .14 & $.33 * *$ \\
\hline Contextual familiarity (CONTEXT) & -.05 & -.04 \\
\hline \multicolumn{3}{|l|}{ Interactions } \\
\hline $\mathrm{CS} \times \mathrm{TIME}$ & & $-.20 *$ \\
\hline $\mathrm{DS} \times \mathrm{TIME}$ & & $.22 *$ \\
\hline $\mathrm{CS} \times \mathrm{CONTEXT}$ & & $.35^{\dagger}$ \\
\hline $\mathrm{DS} \times \mathrm{CONTEXT}$ & & $-.22 *$ \\
\hline $\mathrm{DS} \times \mathrm{CS}$ & & $-.43 * *$ \\
\hline \multicolumn{3}{|l|}{ Covariates } \\
\hline Gender & .06 & .12 \\
\hline Age & $-.02^{\dagger}$ & $-.03 *$ \\
\hline Education & $.75^{* *}$ & $.75^{* *}$ \\
\hline Employment status & -.29 & -.34 \\
\hline Country of residence & $.40^{\dagger}$ & $.44^{\dagger}$ \\
\hline English proficiency & .03 & .03 \\
\hline Search frequency & .07 & $.16^{*}$ \\
\hline Monetary investment & -.08 & -.08 \\
\hline Selection correction $(\lambda)$ & $-.02 *$ & $-.01 *$ \\
\hline Constant & $-4.09 * *$ & $-4.32 * *$ \\
\hline Log-likelihood & -170.7 & -161.8 \\
\hline
\end{tabular}

${ }^{* *} p<.01 ;{ }^{*} p<.05 ;{ }^{\dagger} p<.10$

these interactions, we standardized the measures to aid interpretation [18]. Both models included age, gender, education, employment, country of residence, English proficiency, search frequency, and monetary investment as control variables. A comparison of fit between the two models significantly favored Model 2 (log-likelihood: Model 1 $=-170.7$, Model $2=-161.8, p<.01)$. Thus, we focus on this model to interpret our results.

As shown in Table 2, neither creative nor deliberate problem-solving style has a significant direct effect on solver success. Our results also show that temporal investment has a significant, positive effect on solver success, but contextual familiarity does not. Among the control variables, education and search frequency are positively associated with solver success, whereas age is negatively associated with solver success. In aggregate, solvers who are younger and highly educated, frequently search for challenges, and invest substantial time trying to solve these challenges are more likely to be successful.

Although these direct effects are intriguing, our conceptual focus rests on their interactions. In $\mathrm{H}_{1}$, we proposed that a high 
degree of temporal investment should enhance the success of deliberate styles rather than creative styles. Our results support this hypothesis; the interaction between deliberate styles and temporal investment is positive and significant, whereas the interaction between creative styles and temporal investment is negative and significant. To better understand the nature of these effects, we provide a graphical portrayal of the interaction [38]. Using standardized variables, we created high, medium, and low conditional values for temporal investment across high, medium, and low conditions of both problem-solving styles. As shown in Fig. 1, deliberate styles are more successful when solvers invest more time, but success with creative styles is largely time invariant. Therefore, the analytical, stepby-step nature of deliberate styles is most effective when solvers invest the time necessary to follow these steps in a careful, sequential manner. Conversely, temporal investment is largely unrelated to the intuitive and holistic nature of creative styles.

In our conceptualization, a higher degree of contextual familiarity also should enhance the success of creative styles more than deliberate styles $\left(\mathrm{H}_{2}\right)$. Our results
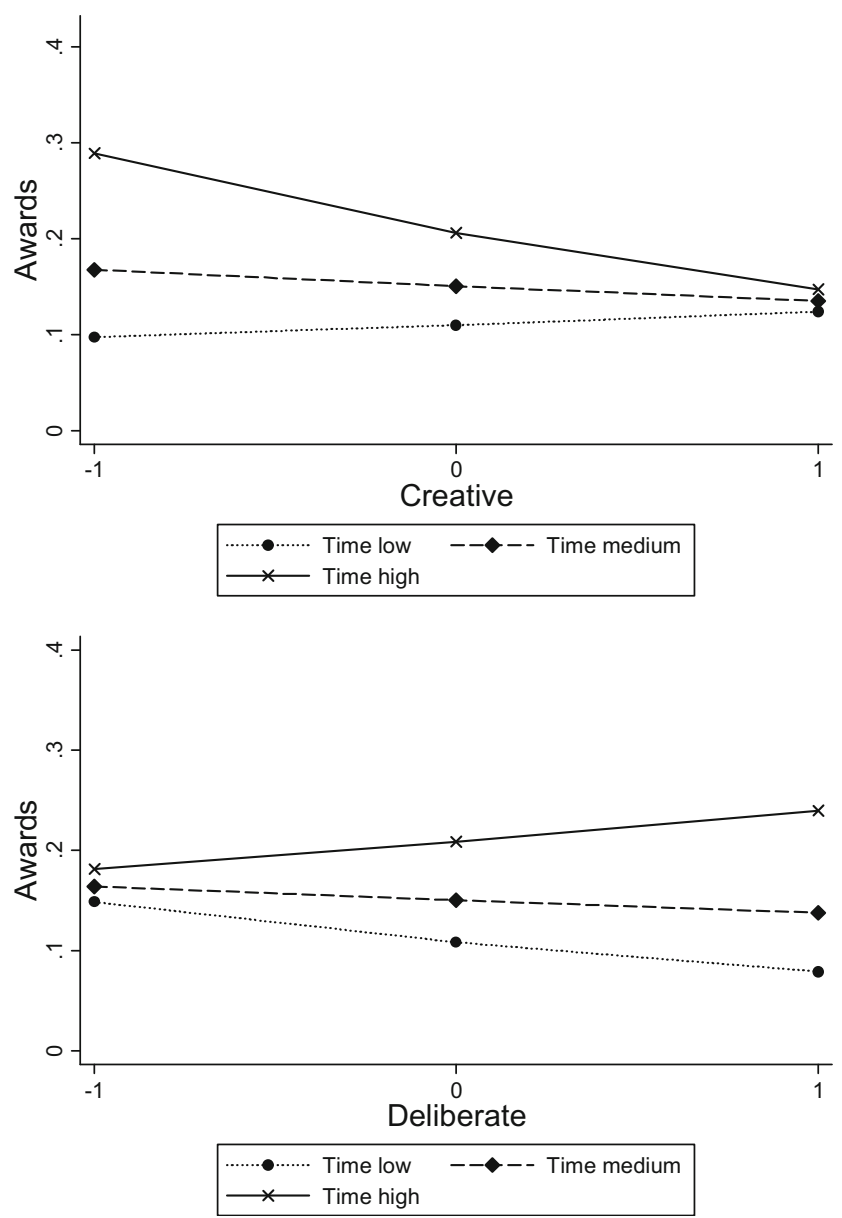

Fig. 1 Interaction between problem-solving styles and temporal investment support this hypothesis: The interaction between creative styles and contextual familiarity is positive and significant, whereas the interaction between deliberate styles and contextual familiarity is negative and significant. We plotted the interaction effects in Fig. 2, which shows that creative styles are more valuable when solvers possess a high degree of contextual familiarity. In contrast, deliberate styles are more valuable when solvers possess lower contextual familiarity.

Finally, $\mathrm{H}_{3}$ predicted that creative and deliberate problem-solving styles are incongruent and that their combination would hamper problem-solving success. Our results confirm this hypothesis; the interaction between creative and deliberate styles is negative and significant. This interaction is graphically portrayed in Fig. 3, which reveals that deliberate styles are most successful when solvers employ a low degree of creative styles. This suggests that in a crowdsourcing setting, the use of both problem-solving styles results in antagonism rather than synergy. In brief, our results indicate that creative flashes of insight and deliberate logic do not appear to mix well and may compromise solution quality.
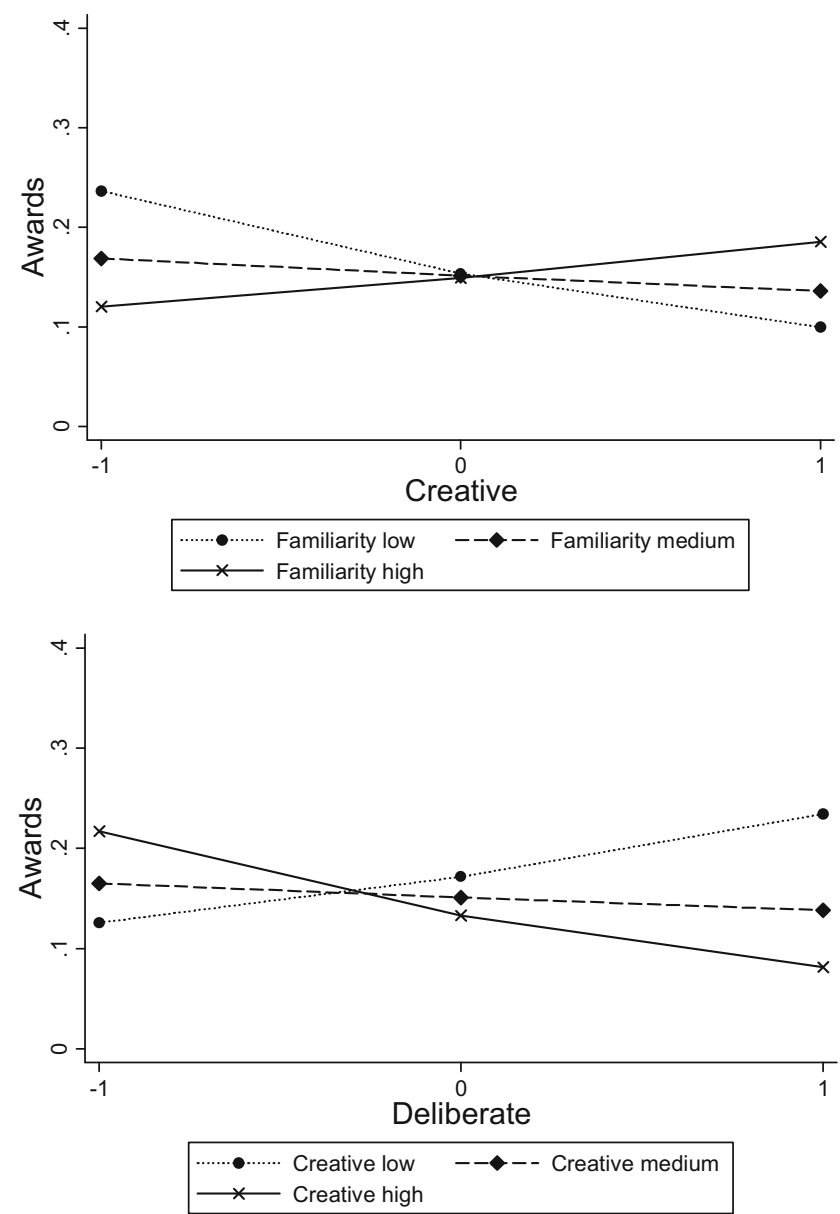

Fig. 2 Interaction between problem-solving styles and contextual familiarity 


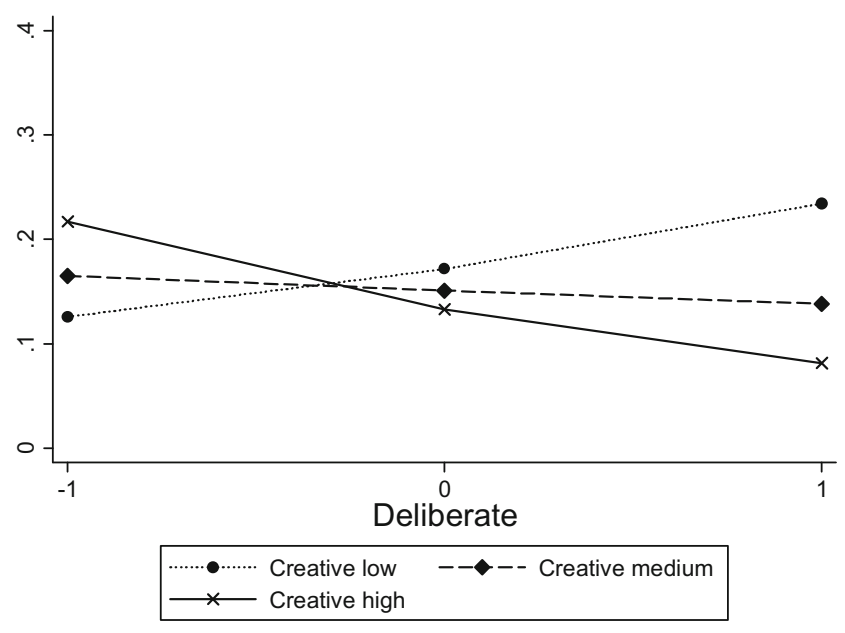

Fig. 3 Interaction etween problem-solving styles

\subsection{Robustness Checks}

We conducted five additional tests to assess the robustness of our findings. First, to ensure that our findings were robust across various types of challenges, we divided our sample (median split) into high and low groups, according to the characteristics (i.e., duration, award size) of the challenges they attempted to solve, then assessed the comparative effect of our key predictors. A $t$ test comparison revealed no significant differences in the impact of our key predictors across these various groups.

Second, to ensure that our findings were robust across solvers with varying levels of solving experience [10], we divided the sample into two categories: novice solvers (i.e., submitted to one challenge, $n=239$ ) and experienced solvers (i.e., submitted to multiple challenges, $n=214$ ). This comparison revealed no significant differences in the impact of any of our key predictors.

Third, to test whether creative and deliberate styles' effectiveness remained stable across multiple submissions, we estimated our ZIP regression model with only solvers who made multiple submissions. Again, the results were similar to those of our focal model.

Fourth, to ensure that our findings were not clouded by potential omitted variable bias, we conducted a latent class analysis using Latent Gold [73]. This analysis estimated the robustness of our results across seven different latent classes (i.e., segments). The results revealed that a one-segment solution displayed the strongest model fit, according to the Akaike information criterion ( -729.18 vs. -720.24 to -675.28 for two- to seven-segment solutions). Thus, omitted variables did not appear to be biasing our results.

Fifth, to ensure that our findings were robust across various model specifications, we reestimated the model using two alternative approaches: a zero-inflated negative binominal regression and a logit regression $[11,72]$. These alternative models showed similar results to those in Table 2, confirming the robustness of our ZIP model results. Overall, these additional tests reveal that our results display a considerable degree of robustness.

\section{Discussion}

In recent years, a growing number of firms have opened their innovation activities by soliciting the skills of external entities (e.g., $[1,2,15])$. Our research explores this intriguing development by examining the effectiveness of innovation crowdsourcing. Our goal was to better understand why some solvers are more successful than others by focusing on their problem-solving styles. Using dual-processing theory as our conceptual lens, we proposed and found that the relative success of creative and deliberate problem-solving styles depends on the amount of time solvers invest in a solution, as well as their degree of contextual familiarity with the problem. Moreover, solvers are less successful when they try to employ both problem-solving styles. These findings provide important implications for both innovation thought and practice and point to interesting directions for further research.

\subsection{Theoretical Contributions}

Research on innovation has long focused on how firms strategize, organize, and execute new product development activities by deploying internal resources and capabilities (e.g., $[53,55,77])$. Our research extends and enriches this body of research by examining how firms develop new products by leveraging external resources and capabilities, in the form of external solvers. Although this topic has attracted some recent attention, research to date has been largely descriptive in nature $[2,14,43,68]$. Our results provide fresh insights by revealing that enduring problem-solving styles exert distinct effects on solver success. Specifically, creative styles are most effective when solvers possess a high degree of contextual familiarity and invest little time developing their solution. In contrast, deliberate styles appear most effective when solvers possess a low degree of contextual familiarity and invest substantial time developing their solution. Considering the relatively low contextual familiarity inherent to most external problem-solving platforms, deliberate styles appear to be an especially important approach. To paraphrase Thomas Edison, "perspiration" appears to be just as (if not more) important than "inspiration."

Our finding regarding the effectiveness of deliberate styles is congruent with a growing body of expertise literature, which suggests that expert performers practice deliberate styles and hone their craft through countless hours of hard work [24, 46, 66]. Despite their importance, deliberate styles have received relatively little attention from many 
contemporary innovation scholars, who instead place more emphasis on the role of creativity for innovation performance in general and problem solving in particular (e.g., [7, 71]). Nonetheless, the value of following a deliberate, sequential approach appears in the use of various techniques for enhancing internal firm-based innovation, such as TRIZ [5], House of Quality [34], and Stage-Gate [20]. Our research suggests that external innovation approaches, like crowdsourcing, may benefit from a greater focus on deliberate styles.

Our results also reveal that these two styles do not work synergistically but are rather antagonistic. Solvers who employ both creative and deliberate styles are less successful than solvers who focus on only one approach. This lack of synergy is also evidenced by the oppositional impact of temporal investment and contextual familiarity across these two styles. This finding has the potential to enrich dual processing literature, which remains largely agnostic regarding the relationship of these two processes [64]. It also provides an interesting contrast to prior research that shows that deliberate and creative styles may be synergistic in internal settings $[40,53]$. Thus, our results reveal important nuances regarding the relationship between these two types of solving styles.

More broadly, our findings suggest that innovation involves a delicate balance between structure and autonomy. Exemplars of structure in new product development settings include TRIZ [5] and House of Quality [34], whereas autonomy is illustrated by techniques such as brainstorming [66] and improvisation [54]. These disparate approaches are seldom intermingled in internal innovation activities. However, in an external problem-solving setting, structure (i.e., deliberate styles) and autonomy (i.e., creative styles) require a careful trade-off. Creative styles may work best when balanced by the structure of a familiar context, whereas deliberate styles may be more effective when operating without this contextual structure. Similar balances also may be important for other forms of open innovation, such as co-creation or lead user innovation $[51,58]$.

Our research lends insights into the role of temporal investment on innovation activity. Innovation scholars traditionally have viewed new product development speed as a critical metric of innovation success [17, 53, 54]. Thus, innovation literature has focused on means to reduce temporal investments by making new product development processes more efficient $[35,75]$. Our findings provide added support for this focus by suggesting that decreased temporal investment might enhance problem-solving success when solvers deploy creative styles. On the other hand, our findings also challenge this focus by indicating that when solvers deploy deliberate styles, solving success can be enhanced through increased temporal investment. This finding is congruent with recent research on serial innovators, which suggests that the people who are most successful at innovating in large, mature organizations invest substantial time to understand the problem before trying to develop a solution [33]. This stark difference in the impact of temporal investments across styles is likely due to the nature of the information processing styles associated with these two problem-solving approaches [64]. Specifically, temporal investment appears to enhance deliberate styles but hamper creative styles. This differential impact provides added nuance to our view of styles and is a topic worthy of greater attention from innovation scholars.

\subsection{Managerial Implications}

Our research is valuable to firms interested in expanding their innovation boundaries by seeking the help of outside experts. In particular, our findings indicate that there are (at least) two paths to solution success: creative inspiration and deliberate perspiration. However, the relative success of each style varies according to a solver's degree of contextual familiarity and temporal investment. Extant research suggests that most external solvers do not know the identity of seeker firms and underinvest the time needed to develop a successful solution [68]. This combination of low contextual familiarity and low temporal investment presents a challenging dilemma, because contextual familiarity is essential for creative styles, and temporal investment is critical for deliberate styles. Consequently, the effectiveness of each solving style is compromised, which may be why the majority of these challenges remain unsolved.

Our research offers insights into some possible remedies for this dilemma. For example, a simple solution would be for seekers to provide a greater amount of contextual familiarity (e.g., information about a problem's background, its expected application, or even the seeker's identity) to enhance the effectiveness of solvers who rely on creative styles. Although this remedy is straightforward and simple, most seekers regard anonymity as a key benefit and guard their identity closely [14]. Thus, seekers may be more interested in motivating solvers who rely on deliberate styles to invest more time developing their solutions. For example, seekers could employ a two-stage submission process, in which a small set of solvers earn intermediate monetary rewards, receive feedback, and are asked to revise their submission.

Assuming that solvers can be motivated to increase their level of temporal investment, deliberate styles offer a more likely route than creative styles to external problem-solving success. Thus, innovation crowdsourcing platforms may want to place more emphasis on identifying and targeting solvers who are likely to display this problem-solving approach. For example, platform providers could ask prospective solvers to respond to our proposed measure of deliberate problemsolving styles and/or encourage them to enact more deliberate styles by requiring them to follow analytical, step-by-step approaches. Our recommendation to assess or stimulate deliberate styles is congruent with growing recognition that their development and deployment is tightly connected to expert performance (e.g., [19]). 


\subsection{Research Directions}

Our research points to several interesting directions for further investigation. First, we examine the influence of two solver styles that are fundamental to crowdsourcing. However, we do not mean to suggest that these two styles are all encompassing. Other potential problem-solving styles might include applying a successful solution from a prior application or experience $[10,50,56]$. Thus, further research that assesses a broader array of problem-solving styles would enrich our inquiry. In addition, although we conceptualize problem-solving styles as relatively enduring traits, it is possible that these styles are more idiosyncratic and that solvers choose problem-solving styles that best match a particular problem's characteristics, such as its degree of difficulty or level of abstraction. Asking respondents about a specific problem-solving incident would allow researchers to probe the intricacies between solver styles and problem characteristics, which could yield interesting insights into the effectiveness of different styles for different types of problems.

Second, we conceptualize creative and deliberate styles as orthogonal, rather than oppositional. The correlation between the styles is significant but modest (see Table 1). Thus, a solver may possess the ability to employ both styles (i.e., to be both deliberate and creative). Our results suggest that although this type of problem-solving ambidexterity is possible, it is not advantageous in an external problem-solving setting (see Fig. 3). However, these two styles might exhibit synergistic effects in other settings [69]. Longitudinal or ethnographic investigations could be especially valuable in teasing out the relationship between these two problem-solving styles and providing a better understanding of their impact across different problem-solving settings.

Third, this research assessed contextual familiarity with a single question that asked participants if they were aware of the identity of the seeker firm. We used this approach because we believe that awareness can be adequately captured using a single-item measure [12]. Nevertheless, we recognize the limits of single-item measures and realize that awareness is only one component of familiarity. Additional research could enrich our work by undertaking a broader examination of contextual familiarity, assessing a solver's knowledge about a seeker's prior solution attempts and its intended uses for the solution.

Fourth, our examination of temporal investment reveals that solvers devote substantial time (i.e., 40 hours, on average) to developing possible solutions for seekers' problems and that this investment enhances the success of solvers who employ deliberate styles. In addition to this time investment, solvers may invest monetary resources to developing a solution. Although our results indicate that monetary investments were unrelated to solving success, prior research suggests that money may enhance the success of both creative and deliberate problem-solving styles [7, 56]. In addition, some challenges may require considerable monetary investments. For example, InnoCentive offered a \$1 million prize for a solution to ALS (Lou Gehrig's disease). Developing a solution to a challenge of this magnitude would require substantial investments of both money and time. While time and money may be metaphorically similar, they differ in many regards. For instance, people are considerably more risk averse in their monetary investments than in their time investments [59]. Thus, further research would be useful in exploring the role of monetary investments and examining the degree to which they can substitute, complement, or even impede the impact of temporal investments on problem-solving success.

\subsection{Conclusion}

In conclusion, our investigation reveals that creative and deliberate problem-solving styles can be effective approaches for innovation crowdsourcing. However, their effectiveness depends on a solver's degree of temporal investment and contextual familiarity. These findings are congruent with dual-processing theory and provide initial insights into how solver practices affect innovation success. We hope this study motivates and guides further research in this intriguing domain.

Acknowledgments The authors thank seminar participants at Eindhoven University of Technology, Ewha Woman's University, London Business School, Pennsylvania State University, RWTH Aachen University, Sungkyunkwan University, Temple University, and University of IllinoisChicago for their many useful suggestions. Kersi Antia, Jim Burroughs, Karim Lakhani, Annouk Lievens, Andrea Lind, and Vivian Zheng provided helpful comments, and Peter Lohse offered access to the InnoCentive data.

\section{Appendix. Survey Measures}

\section{Creative Problem-Solving Styles}

Adapted from Amabile [6], Besemer and O'Quin [13], and Sloman [64]

1. I use knowledge outside my domain.

2. I develop a large number of alternative Challenge solutions.

3. I try to think of solutions that no one else will think of.

4. I look for creative solutions.

5. I also generate ideas for other solutions.

6. I try to think "outside the box" when considering different possible solutions. 


\section{Deliberate Problem-Solving Styles}

Adapted from Ericsson et al. [24], Allinson and Hayes [4], and Sloman [64]

1. I always pay attention to the details of the Challenges before I reach a conclusion.

2. When solving Challenges, I take my time and thoroughly consider all relevant information.

3. My solving of Challenges tends to rely more on thorough analysis than flashes of insight.

4. The kind of Challenge solving I like best is that which requires a logical, step-by-step approach.

5. I make quick decisions rather than analyze every last detail of the Challenges. (Reversed)

6. I am careful to follow the requirements set by the Challenge criteria.

\section{References}

1. Abrahamson S, Ryder P, Unterberg B (2013) Crowdstorm: the future of innovation, ideas, and problem solving. Wiley, New York

2. Afuah A, Tucci CL (2012) Crowdsourcing as a solution to distant search. Acad Manag Rev 37(3):355-375

3. Ahuja G, Katila R (2001) Technological acquisitions and the innovation performance of acquiring firms: a longitudinal study. Strateg Manag J 22(3): 197-220

4. Allinson CW, Hayes J (1996) The cognitive style index: a measure of intuition-analysis for organizational research. J Manag Stud 33(1): 119-135

5. Altshuller G (1984) Creativity as an exact science. Gordon \& Breach, New York

6. Amabile TM (1983) The social psychology of creativity: a componential conceptualization. J Pers Soc Psychol 45(2):357-376

7. Amabile TM, Conti R, Coon H, Lazenby J, Herron M (1996) Assessing the work environment for creativity. Acad Manag $\mathrm{J}$ 39(5):1154-1184

8. Ansburg PI, Hill K (2003) Creative and analytical thinkers differ in their use of attentional resources. Personal Individ Differ 34:11411152

9. Armstrong SJ, Overton TS (1977) Estimating nonresponse bias in mail surveys. J Mark Res 17(3):396-402

10. Bayus BL (2013) Crowdsourcing new product ideas over time: an analysis of the Dell IdeaStorm community. Manag Sci 59(1):226244

11. Benner MJ (2009) Dynamic or static capabilities? Process management practices and response to technological change. J Prod Innov Manag 26(5):473-486

12. Bergkvist L, Rossiter JR (2007) The predictive validity of multiple versus single-item measures of the same constructs. J Mark Res 44(3):175-184

13. Besemer S, O'Quin K (1986) Analyzing creative products: refinement and test of a judging instrument. J Creat Behav 20(2):115-126

14. Billington C, Davidson R (2010) Using knowledge brokering to improve business processes. McKinsey Quarterly (January): 1-8

15. Boudreau KJ, Lacetera N, Lakhani KR (2011) Incentives and problem uncertainty in innovation contests: an empirical analysis. Manag Sci 57(5):843-863
16. Burroughs JE, Moreau CP, Mick DG (2008) Towards a psychology of consumer creativity. In: Haugtvedt CP, Herr PM, Kardes FR (eds) Handbook of consumer psychology. Lawrence Erlbaum, New York, pp 1011-1038

17. Chesbrough HW (2003) Open innovation: the new imperative for creating and profiting from technology. Harvard Business School Press, Boston

18. Cohen JP, Cohen SG, West SG, Aiken LS (2003) Applied multiple regression/correlation analysis for the behavioral sciences. Lawrence Erlbaum Associates, Mahwah

19. Colvin G (2008) Talent is overrated. Portfolio, New York

20. Cooper RG (2008) The stage-gate idea-to-launch process: update, what's new, and nexgen systems. J Prod Innov Manag 25(3):213-232

21. Dittrich K, Duysters G (2007) Networking as a means to strategy change: the case of open innovation in mobile telephony. J Prod Innov Manag 24(6):510-521

22. Emden Z, Calantone RJ, Droge C (2006) Collaborating for new product development: selecting the partner with maximum potential to create value. J Prod Innov Manag 23(4):330-341

23. Epstein S, Pacini R, Denes-Raj V, Heier H (1996) Individual differences in intuitive-experiential and analytical-rational thinking styles. J Pers Soc Psychol 71(2):390-405

24. Ericsson KA, Krampe RT, Tesch-Römer C (1993) The role of deliberate practice in the acquisition of expert performance. Psychol Rev 100(3):363-406

25. Felin T, Hesterly WS (2007) The knowledge-based view, nested heterogeneity, and new value creation: philosophical considerations on the locus of knowledge. Acad Manag Rev 32(1):195-218

26. Fornell C, Larcker DF (1981) Evaluating structural equation models with unobservable variables and measurement error. J Mark Res 18(1):39-50

27. Garen J (1984) The returns to schooling: a selectivity bias approach with a continuous choice variable. Econometrica 52(5):1199-1218

28. Ghosh M, Dutta S, Stremersch S (2006) Customizing complex products: when should the vendor take control? J Mark Res 43(4):664 679

29. Girotra K, Terwiesch C, Ulrich KT (2010) Idea generation and the quality of the best idea. Manag Sci 56(4):591-605

30. Goldenberg J, Mazursky D (2002) Creativity in product innovation. Cambridge University Press, Cambridge

31. Goldman R, Gabriel RP (2005) Innovation happens elsewhere. Morgan Kaufmann, San Francisco

32. Greene WH (1994) Accounting for excess zeros and sample selection in poisson and negative binomial regression models. NYU Working Paper EC-94-10, New York University

33. Griffin A, Sim EW, Price R, Vojak B (2007) Exploring differences between inventors, champions, implementors, and serial innovators in developing new products in large mature firms. Creat Innov Manag 16(4):422-436

34. Hauser JR, Clausing D (1988) The house of quality. Harv Bus Rev 66(3):63-73

35. Hauser J, Tellis GJ, Griffin A (2006) Research on innovation: a review and agenda for marketing science. Mark Sci 25(6):687-717

36. Heckman JJ (1979) Sample selection bias as a specification error. Econometrica 47(1):153-161

37. Hirschman EC (1980) Innovativeness, novelty seeking, and consumer creativity. J Consum Res 7(3):283-295

38. Hoetker G (2007) The use of logit and probit models in strategic management research: critical issues. Strateg Manag J 28(4):331-343

39. Hogarth R (2002) Deciding analytically or trusting your intuition? The advantages and disadvantages of analytic and intuitive thought. UPF Economics and Business Working Paper No. 654, Barcelona, Spain

40. Hoffman DL, Kopalle PK, Novak TP (2010) The "right" consumers for better concepts: identifying consumers high in emergent nature to develop new product concepts. J Mark Res 47(3):854-865 
41. Huston L, Sakkab N (2006) Connect and develop. Harv Bus Rev 84(3):58-66

42. IBM (2012) Global CEO study: leading through connections. IBM Global Business Services, Somers

43. Jeppesen LB, Lakhani KR (2010) Marginality and problem solving effectiveness in broadcast search. Organ Sci 21(5):1016-1033

44. Jöreskog KG, Sörbom D (1993) LISREL 8: structural equation modeling with the SIMPLIS command language. Scientific Software, Chicago

45. Kahneman D (2003) A perspective on judgment and choice: mapping bounded rationality. Am Psychol 58(9):697-720

46. Kahneman D (2011) Thinking, fast and slow. Farrar, Straus and Giroux, New York

47. Kirton MJ (1989) Adaptors and innovators: styles of creativity and problem-solving. Routledge, New York

48. Lakhani KR (2008) InnoCentive.com (A). Harvard Business School Case 9-608-170. Harvard Business School Publishing, Boston

49. Laursen K, Salter A (2006) Open for innovation: the role of openness in explaining innovation performance among UK manufacturing firms. Strateg Manag J 27(2):131-150

50. Magnusson PR (2009) Exploring the contributions of involving ordinary users in ideation of technology-based services. J Prod Innov Manag 26(5):578-593

51. Mahr D, Lievens A, Blazevic V (2014) The value of customer cocreated knowledge during the innovation process. J Prod Innov Manag 31(3):599-615

52. McDonough EF III (1990) An investigation of the relationship between project performance and characteristics of project leaders. J Eng Technol Manag 6(3):237-260

53. McDonough EF III, Barczak G (1992) The effects of cognitive problem-solving orientation and technological familiarity on faster new product development. J Prod Innov Manag 9(1):44-52

54. Moorman C, Miner AS (1998) Organizational improvisation and organizational memory. Acad Manag Rev 23(4):698-723

55. Moorman C, Slotegraaf RJ (1999) The contingency value of complementary capabilities in product development. J Mark Res 36(2):239257

56. Newell A, Simon HA (1972) Human problem solving. Prentice-Hall, Englewood Cliffs

57. Novak TP, Hoffman DL (2009) The fit of thinking style and situation: new measures of situation-specific experiential and rational cognition. J Consum Res 36(1):56-72

58. O'Hern MS, Rindfleisch A (2010) Customer co-creation: a typology and research agenda. In: Malholtra NK (ed) Review of marketing research, volume 6. M.E. Sharpe, Armonk, pp 84-106

59. Okada E, Hoch SJ (2004) Spending time versus spending money. J Consum Res 31(1):313-323
60. Podsakoff PM, MacKenzie SB, Lee J, Podsakoff NP (2003) Common method biases in behavioral research: a critical review of the literature and recommended remedies. J Appl Psychol 88(5): 879-903

61. Poetz MK, Prügl R (2010) Crossing domain-specific boundaries in search of innovation: exploring the potential of pyramiding. J Prod Innov Manag 27(6):897-914

62. Prietula MJ, Simon HA (1989) The experts in your midst. Harv Bus Rev 67(1):120-124

63. Rindfleisch A, Moorman C (2001) The acquisition and utilization of information in new product alliances: a strength-of-ties perspective. $\mathrm{J}$ Mark 65(2):1-18

64. Sloman SA (1996) The empirical case for two systems of reasoning. Psychol Bull 119(1):3-22

65. Smith ER, DeCoster J (2000) Dual-process models in social and cognitive psychology: conceptual integration and links to underlying memory systems. Personal Soc Psychol Rev 4(2): 108-131

66. Sternberg RJ (1999) Handbook of creativity. Cambridge University Press, Cambridge

67. Teece D (2003) Expert talent and the design of (professional services) firms. Ind Corp Chang 12(4):895-916

68. Terwiesch $\mathrm{C}, \mathrm{Xu}$ Y (2008) Innovation contests, open innovation, and multiagent problem solving. Manag Sci 54(9):1529-1543

69. Tushman ML, O'Reilly CA (2006) Winning through innovation. Harvard Business Press, Boston

70. Verona G, Prandelli E, Sawhney M (2006) Innovation and virtual environments: towards virtual knowledge brokers. Organ Stud 27(6):765-788

71. von Hippel E (2005) Democratizing innovation. MIT Press, Cambridge

72. von Wangenheim F, Bayón T (2007) The chain from customer satisfaction via word-of-mouth referrals to new customer acquisition. J Acad Mark Sci 35(2):233-249

73. Wang R, Saboo AR, Grewal R (2015) A managerial capital perspective on chief marketing officer succession. International Journal of Research in Marketing, forthcoming

74. West J, Bogers M (2014) Leveraging external sources of innovation: a review of research on open innovation. J Prod Innov Manag 31(4): 814-831

75. Wheelwright SC, Clark KB (1992) Revolutionizing product development. The Free Press, New York

76. Woodman RW, Sawyer JE, Griffin RW (1993) Toward a theory of organizational creativity. Acad Manag Rev 18(2):293-321

77. Zollo M, Winter SG (2002) Deliberate learning and the evolution of dynamic capabilities. Organ Sci 13(3):339-351 